\title{
Slow Transit Constipation Associated With Excess Methane Production and Its Improvement Following Rifaximin Therapy: A Case Report
}

\author{
Uday C Ghoshal, ${ }^{*}$ Deepakshi Srivastava, Abhai Verma and Asha Misra \\ Department of Gastroenterology, Sanjay Gandhi Post Graduate Institute of Medical Sciences Lucknow, India
}

Constipation, a common problem in gastroenterology practice, may result from slow colonic transit. Therapeutic options for slow transit constipations are limited. Excessive methane production by the methanogenic gut flora, which is more often found in patients with constipation, slows colonic transit. Thus, reduction in methane production with antibiotic treatment directed against methanogenic flora of the gut may accelerate colonic transit resulting in improvement in constipation. However, there is not much data to prove this hypothesis. We, therefore, report a patient with slow transit constipation associated with high methane production both in fasting state and after ingestion of glucose, whose constipation improved after treatment with non-absorbable antibiotic, rifaximin, which reduced breath methane values.

(J Neurogastroenterol Motil 2011;17:185-188)

Key Words

Breath tests; Constipation; Hydrogen; Irritable bowel syndrome; Methane

\section{Introduction}

Chronic constipation, a common problem all over the world, may be caused by slow colonic transit. Excessive methane production due to presence of methanogenic flora in the gut may cause slowing of gut transit. ${ }^{1}$ In patients with irritable bowel syndrome (IBS), who had excess methane on lactulose hydrogen breath test, presence and degree of constipation correlated with methane production both subjectively and objectively. ${ }^{2}$ In another study, methane production after carbohydrate challenge was higher in patients with slow transit constipation than in those with normal transit, though stool characteristics were similar in both groups. ${ }^{3}$ Methane production correlated with colonic transit, suggesting an association with stool transport but not with stool characteristics. ${ }^{3}$ In a study of an animal model, infusion of methane gas into gut slowed down its motility. These data suggested that methane gas slowed gut transit, while its effect on stool form and consistency was somewhat contradictory. Moreover, there is no data on the use of methane-reducing drugs that modulate gut flora and their effect on colonic transit and stool form. We report a patient with slow transit constipation associated with excess

Received: February 16, 2011 Revised: February 21, 2011 Accepted: February 23, 2011

(c) This is an Open Access article distributed under the terms of the Creative Commons Attribution Non-Commercial License (http://creativecommons. org/licenses/by-nc/3.0) which permits unrestricted non-commercial use, distribution, and reproduction in any medium, provided the original work is properly cited.

*Correspondence: Uday C Ghoshal, MD, DNB, DM, FACG

Department of Gastroenterology, Sanjay Gandhi Post Graduate Institute of Medical Sciences, Lucknow 226014, India Tel: +91-962-8842456, Fax: +91-522-2668017 (or 2668078), E-mail: udayghoshal@gmail.com

Financial support: This work was supported by extramural research grants (No. SR/S0/HS/-15/2007) from the Department of Science and Technology, Government of India to UCG.

Conflicts of interest: None. 
methane production; her stool form and frequency improved after reduction of methane production using gut specific antibiotic, which also accelerated colonic transit.

\section{Case Report}

A 57-year old female presented to us with constipation, post-prandial epigastric fullness, tiredness, nausea and belching. These symptoms were present for more than 15 years without any significant change in severity. She used to pass stool every 2 to 3 days and had feeling of incomplete evacuation. Stools were hard, lumpy, which were difficult to pass (Bristol type I, Figure). ${ }^{5}$ She denied evacuating manually or having rectal prolapse. Alarm features such as unintentional weight loss, bleeding per rectum, severe abdominal pain and anorexia were absent. There was no family history of colonic malignancy. She did not have vomiting. She had 4 children and underwent hysterectomy 20 years ago for symptomatic fibroid. She underwent surgical treatment for left para-sellar cavernous hemangioma 6 months ago. Laboratory findings revealed mild anemia (hemoglobin $10.0 \mathrm{~g} / \mathrm{dL}$ ), fasting blood sugar $88 \mathrm{mg} / \mathrm{dL}$, serum creatinine $0.7 \mathrm{mg} / \mathrm{dL}$, serum albumin $4.0 \mathrm{~g} / \mathrm{dL}$ and normal thyroid stimulating hormone level (2.82 mIU/L). Colonoscopy showed a diminutive polyp in rectum, which was a hyperplastic polyp on histology (Figure). Colonic transit time using a previously validated protocol (20 markers each at 0,12 and 24 hour; abdominal radiographs at 36 and 60 hour) showed 54 of 60 markers retained at 60 hour (abnormal > 14 markers) suggestive of slow colonic transit (Figure). ${ }^{6}$ Radionuclide gastric emptying study using technetium 99-m sulfur colloid labeled standard solid meal showed clearance half time of 61 minutes (normal $83 \pm 13$ minutes). ${ }^{7}$ Glucose hydrogen breath test using a standard protocol (Quin Tron Breathtracker $^{\mathrm{TM}}$ Digital Microlyzer, QuinTron Inc, Milwaukee, WI, USA) revealed rise in breath hydrogen from 13 parts per
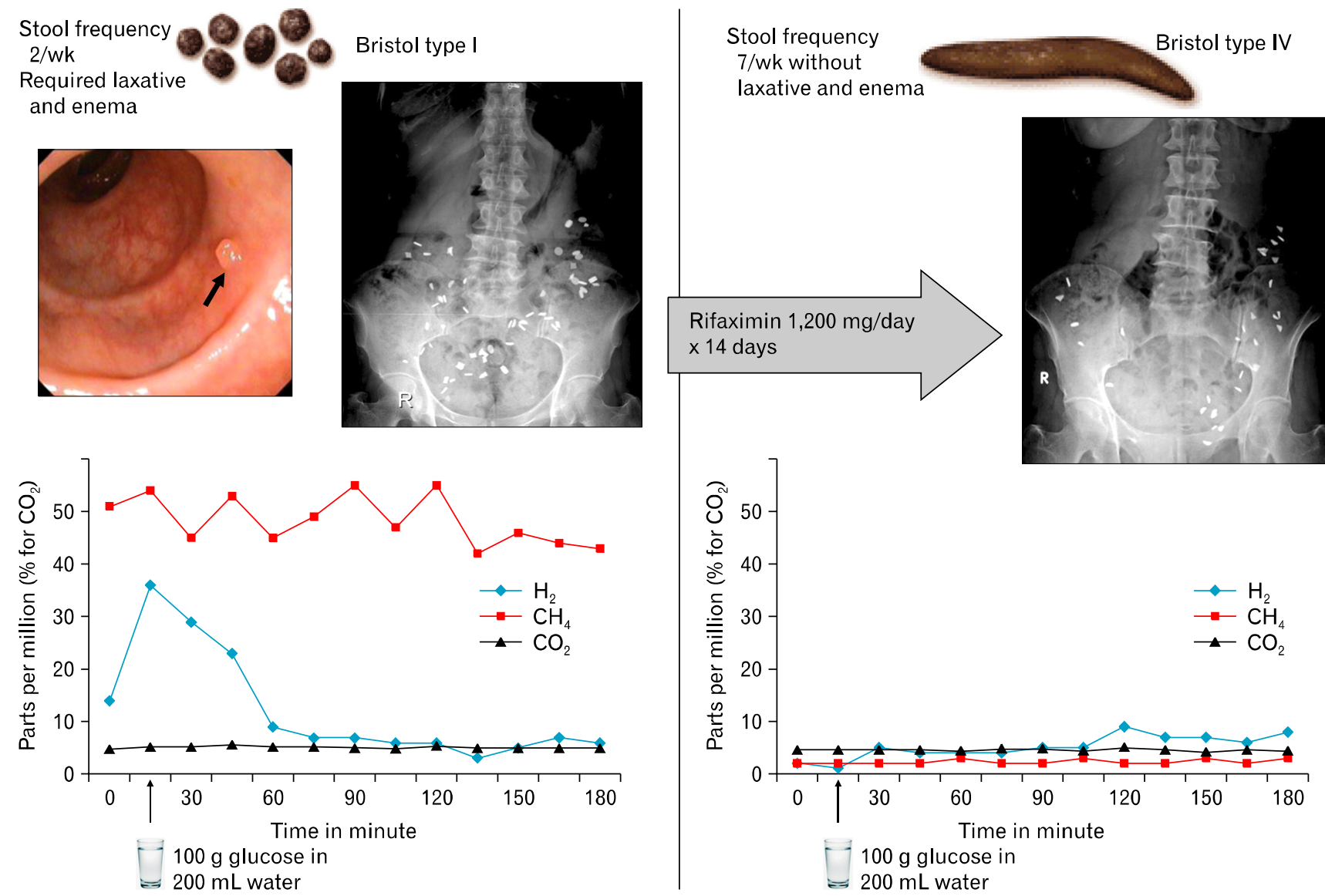

Figure. Effect of rifaximin on stool form and frequency, breath methane and colonic transit as assessed by radio-opaque markers in a patient with slow transit constipation associated with high breath methane in fasting state and following ingestion of $100 \mathrm{~g}$ glucose (left panel: before treatment; right panel: after rifaximin). The patient also had a diminutive polyp in rectum on colonoscopy (indicated by arrow). 
million (ppm) in fasting state to $36 \mathrm{ppm}$ after ingestion of $100 \mathrm{~g}$ glucose (abnormal $>12$ ppm than basal) suggesting small intestinal bacterial overgrowth (Figure; sensitivity $44 \%$ and specificity $80 \%) .{ }^{8}$ She had high methane excretion in breath (50 ppm) both in fasting state and after ingestion of glucose suggesting presence of methane producing bacteria in the gut (Figure). Since methane is known to reduce gut transit that may result in constipation, she was treated with rifaximin 1,200 mg per day in 3 divided doses for 14 days to reduce methane in her gut. Her symptoms improved with stool frequency of 1 per day of Bristol type IV without laxative and enema (Figure). CTT was repeated to reassess colonic transit, which showed 30 of 60 markers retained after 60 hours (Figure). Glucose hydrogen breath test repeated after 2 weeks did not show small intestinal bacterial overgrowth and methane excretion in breath was low ( $<5$ ppm, Fi gure). At this stage, she was prescribed with low-dose tegaserod, which is known to prevent recurrence of symptoms following treatment directed to small intestinal bacterial overgrowth. ${ }^{9}$ She remained well during 2-month follow-up.

\section{Discussion}

Our patient had slow-transit constipation as evidenced by stool frequency less than 3 per week, hard stools (Bristol type I), need for laxative and enema with retention of 54 of 60 markers at 60 hour abdominal radiograph. She had high quantity of methane in exhaled air both at fasting state and after ingestion of glucose. We hypothesized that high amount of methane could slow down her gut transit causing constipation; association between high breath methane and slow colonic transit resulting in constipation has been described in literature. Our hypothesis was further supported by improvement of colonic transit and consequent improvement in stool frequency and form after reduction in methane excretion by treatment with rifaximin.

Methane production in the gut is known to be associated with slow gut transit. Previous studies showed that methane production in IBS patients was almost universally associated with constipation and lumpy stools. ${ }^{2,10}$ In contrast, patients with diarrhea usually have higher excretion of hydrogen in breath both during fasting state and following administration of glucose. ${ }^{11,12}$ Methane was associated with presence and degree of constipation both subjectively and objectively in a study on 87 IBS patients, 20 (24\%) of whom produced methane on lactulose hydrogen breath test. ${ }^{2}$ In another study, methane production after carbohydrate challenge correlated with colonic transit but not with stool characteristics. ${ }^{3}$ The mechanism of slow colonic transit due to excess methane in the gut might be related to abnormality in intestinal motility and reduction in serotonin production.

Our patient had slow transit constipation and excess methane production both in fasting state and following challenge with glucose. Slow colonic transit and constipation in our patient might result from excess methane gas in her gut as both constipation and colonic transit improved after reduction of methane gas with treatment of rifaximin. Recently, in 2 identically designed phase 3, double-blind, placebo-controlled trials, IBS patients without constipation, treatment with rifaximin for 2 weeks provided significant relief of IBS symptoms, bloating, abdominal pain, and loose or watery stools. ${ }^{13}$ However, the present case suggests that even constipation resulting from slow motility due to excess methane production may improve after treatment with rifaximin.

In conclusion, the present case report suggests that constipation resulting from slow transit due to excess methane production in gut may respond to treatment with antibiotics such as rifaximin, which reduces methane production by reducing the methanogenic flora in the gut. Further study in the form of a randomized controlled trial is required to substantiate this finding.

\section{References}

1. Hwang L, Low K, Khoshini R, et al. Evaluating breath methane as a diagnostic test for constipation-predominant IBS. Dig Dis Sci 2010; 55:398-403.

2. Chatterjee S, Park S, Low K, Kong Y, Pimentel M. The degree of breath methane production in IBS correlates with the severity of constipation. Am J Gastroenterol 2007;102:837-841.

3. Attaluri A, Jackson M, Valestin J, Rao SS. Methanogenic flora is associated with altered colonic transit but not stool characteristics in constipation without IBS. Am J Gastroenterol 2010;105:1407-1411.

4. Pimentel M, Lin HC, Enayati $\mathrm{P}$, et al. Methane, a gas produced by enteric bacteria, slows intestinal transit and augments small intestinal contractile activity. Am J Physiol Gastrointest Liver Physiol 2006; 290:G1089-G1095.

5. Valerio F, Russo F, de Candia S, et al. Effects of probiotic Lactobacillus paracasei-enriched artichokes on constipated patients: a pilot study. J Clin Gastroenterol 2010;44(suppl 1): S49-S53.

6. Ghoshal UC, Gupta D, Kumar A, Misra A. Colonic transit study by radio-opaque markers to investigate constipation: validation of a new protocol for a population with rapid gut transit. Natl Med J India 2007;20:225-229.

7. Mittal BR, Wanchu A, Das BK, Ghosh PP, Sewatkar AB, Misra $\mathrm{RN}$. Pattern of gastric emptying in patients with systemic sclerosis. 
Clin Nucl Med 1996;21:379-382.

8. Ghoshal UC, Ghoshal U, Das K, Misra A. Utility of hydrogen breath tests in diagnosis of small intestinal bacterial overgrowth in malabsorption syndrome and its relationship with oro-cecal transit time. Indian J Gastroenterol 2006;25:6-10.

9. Pimentel M, Morales W, Lezcano S, Sun-Chuan D, Low K, Yang $\mathrm{J}$. Low-dose nocturnal tegaserod or erythromycin delays symptom recurrence after treatment of irritable bowel syndrome based on presumed bacterial overgrowth. Gastroenterol Hepatol (N Y) 2009;5: 435-442.

10. Grover M, Kanazawa M, Palsson OS, et al. Small intestinal bacterial overgrowth in irritable bowel syndrome: association with colon mo- tility, bowel symptoms, and psychological distress. Neurogastroenterol Motil 2008;20:998-1008.

11. Ghoshal UC, Kumar S, Mehrotra M, Lakshmi C, Misra A. Frequency of small intestinal bacterial overgrowth in patients with irritable bowel syndrome and chronic non-specific diarrhea. J Neurogastroenterol Motil 2010;16:40-46.

12. Kumar S, Misra A, Ghoshal UC. Patients with irritable bowel syndrome exhale more hydrogen than healthy subjects in fasting state. $\mathrm{J}$ Neurogastroenterol Motil 2010;16:299-305.

13. Pimentel M, Lembo A, Chey WD, et al. Rifaximin therapy for patients with irritable bowel syndrome without constipation. $\mathrm{N}$ Engl J Med 2011;364:22-32. 